\title{
Pengaruh Disiplin Kerja, Motivasi Kerja Terhadap Kinerja Karyawan Glory Store Indonesia
}

\author{
Fahmi Susanti
}

Universitas Pamulang, dosen02024@unpam.ac.id

\begin{tabular}{ll}
\hline ARTICLES & ABSTRACT \\
INFORMATION & \\
\hline
\end{tabular}

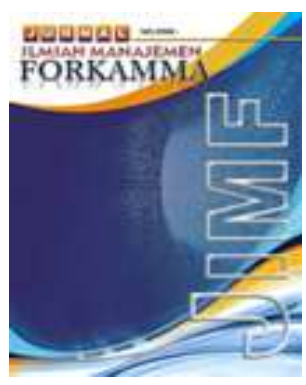

JURNAL ILMIAH MANAJEMEN FORKAMMA

Vol.4, No.3, Juli 2021

Halaman : $278-287$

(C) LPPM \& FORKAMMA

Prodi Magister Manajemen

UNVERSITAS PAMULANG

ISSN (online) : 2599-171X

ISSN (print) : :2598-9545

Keyword :

Desiplin; Motivasi; Kinerja

JEL. classification :

O15,

\section{Contact Author :}

\section{PRODI}

\section{MAGISTER MANAJEMEN \& FORKAMMA UNPAM}

JL.Surya Kencana No.1 Pamulang

Tangerang Selatan - Banten

Telp. (021) 7412566, Fax (021) 7412491 Email :

jurnalforkamma.unpam@gmail.com
Goal penelitian ialah untuk menganalisis dan mengidetifikasi disiplin kerja, dorongan kerja terhadap hasil kerja. Enam bulan ialah waktu yang dipakai untuk melakukan penelitian pada responden berjumlah 67 orang memakai metode kuantitatif yang mana teknik ini merupakan tahap peendekatan, penilaian didapat berdasar skor melalui kalkulasi statistic. Teknik mengumpulkan data, riset kepustakaan, riset lapangan, pengalaman saat beraktivitas, serta kuesioner ialah berbagai teknik yang dipakai. Analisis data memakai "metode kuantitatif" yang berkarakteristik bisa dinilai melalui skor, di dalamnya terdiri dari uji normallitas, uji validiitas, uji reliabilitas, serta uji pengaruh. Dilakukan pembagian pernyataan pada 67 responden, target harus menjawabnya dengan jujur. Adanya dampak disipln, dorongan kerja kepada hasil kerja.

\section{Keywords: Disipilin; Motivasi; Kinerja}

The study objective is to investigate and identify the work selfrestraint of the environment and the work outcome of workers. 6 months was the time spent conducting study on 67 respondents using quantitative methods where this technique was an approach stage, assessments are made based on scores through statistical calculations. Data accumulation techniques, library research techniques, field research techniques, experience in action, and questionnaire techniques are various techniques used in data accumulation. Data analysis using quantitative methods with characteristics can be assessed through a score which consists of a normality test, a validity test, a reliability test, and an impact test. Questionnaires were dispensed to 67 respondents, each question must be answered honestly by the target

\section{Keywords: Work Discipline; Motivation; Empolyee Performance}




\section{A. PENDAHULUAN}

Terkait goal yg harus diraih industri atau perserikatan atas beragam rupa persoalan ataupun perkara kasus lokal di industri juga kasus non lokal, pelbagai ketidaktegasan serta kelalaian dalam penyelesaian perkara kasus akan menambah rumit kondisi yang ada. Bisa dipahami bertapa pentingnya sikap tanggap dan ketepatan dalam menguraikan dan memperhatikan perkara yang ditemukan Peran dari daya tenaga manusia teramat sangat penting pada aktivitas industry atau perserikatan ini, baik di saat mengoperasikan tugasnya, melayani pelanggan, mengaplikasikan manajemen industry. Instrumen yang modern kurang berarti jika tidak ada andil dari tenaga manusianya. Hakikatnya daya pekerjalah yang membangun rencana, merumuskan, mengoperasikan sampai mengevaluasi dengan support dari kemodernan instrumen dan media yang tersedia tersebut. Dengan alasan di atas, ketentraman dan keselamatan tenaga kerja harus diprioritaskan sebagai pendorong kekreativitasan.

Untuk bisa selalu adaptasi dengan transformasi sains secara global, industry harus mempunyai prestasi kerja yang cemerlang. Performa ini bisa diraih dengan menyediakan pemicu semangat pekerja dalam prioritas utama dalam bentuk kesejahteraan, ketenangan secara materi atau non materi. Penyemangat tersebut akan memacu pekerja untuk lebih giat dan serius dalam penyelesaian peran dan tugas masing-masing. Kebalikannya, bila pemicu semangat ini tidak dipedulikan maka dipastikan hubungan tim yang terjadi di lingkunga pekerjaan tidak menyenangkan, timbul kemerosotan performa dan hasil akhir pekerja. Pandangan ini seusai dengan kaidah dasar ilmiah. Ada berbagai sebab dalam kerelecanan tugas di industry di antaranya, sikap saling menghargai yang kurang, keraguan pekerja akan pemberian dan transparansi benefit atas usaha yang telah mereka lakukan untuk majunya industry, tindakan negative dari atasan, arahan atas tugas kurang. Semua gangguan ini harus dihindari, semua persoalan tersebut akan berakibat keburukan dan lambatnya aktivitas pekerja, berefek besar pada keeksisan indutri. Kapasitas industry akan tercapai maksimum, bila pekerja punya kesamaan misi dengan industrinya dan pemberian jaminan kesejahteraan dari industrinya, dengan tercukupinya kesejahteraan tersebut akan dengan sendirinya timbul tabiat disiplin dalam tugasnya dan memberikan performa yang membanggakan, keahlian serta kemahiran, konsep diri yang positif. Untuk mengimbanginya, industry harus mengembangkan kapabilitas, kapasitas, kecakapan, dan daya pekerja. Teknik yang bisa dilakukan yaitu pelatihan Pendidikan, promosi magang, diikutsertakan dalam seminar, temukan potensi yang ada untuk menghasilkan nilai tambah, melimpahkan wewenang, atasan memberi teladan serta bimbingan positif. Pelatihan yang ditawarkan harus cocok dengan apa yang dibutuhkan industry saat itu dan disesuaikan dengan daya yang dimiliki pekerjanya. Bimbingan positif dan arahan itu.

\section{Perbatasan Masalah}

Dengan alasan banyaknya jangkauan bahasan serta menjauhi kesalah pahaman persepsi maka dilakukan batasan secara spesifikasi problem.

1. Kedisiplinan ialah suatu bentuk bertautan pada penanganan diri yang terjadi secara ikhlas. Alur sikap akan penetapan pandangan aturan, prinsip, kaidah, syarat, dan larangan. Caranya berupa harus tertanamnya persepsi bahwa semua perbuatan di atas adalah mempunyai dampak manfaat bagi dirinya. 
2. Ambisi kerja ialah pemicu sugesti, kondisi yang mengarahkan kecakapan dirinya untuk terlaksananya goal akhir industry. Semua ini memupuk dan menumbuhkan antusiasme dalam beraktivitas.

3. Hasil kerja: iklim konteks lingkungan sebagai akhir perolehan kerja. Konteks akhir ini harus dilaporkan, diinformasikan, dan diterangkan pada industry bersangkutan gunanya untuk menginformasikan dan memprediksi hasil akhir tugas, apakah sudah sesuai dengan rencana pandagan industry. Selain itu, bisa digunakan sebagai bahan perhitungan dan pengukuran prestasi industry maupun prestasi pekerja dan bisa diestimasi apakah strategi yang diimplementasikan ini berimbas baik atau buruk.

4. Posisi Penelitian di Glory Store Indonesia, riset dimulai 1 Januari - Juni 2021.

\section{Manfaat}

Kegunaan selain bisa terlaksananya tujuan yang sudah dipaparkan, diharap ada kebermanfaatan lainnya:

1. Menambah luasnya pandangan penulis berkenaan disiplin, dorongan motivasi, dan hasil kerja. Wawasan ini bisa dipraktikkan dan diaplikasikan pada tempat berkarirnya dan pada projek yang ada.

2. Sebagai sumbangan dan memberi andil keilmuan pembaca

\begin{tabular}{|lllll|}
\hline $\begin{array}{l}\text { Pengaruh } \\
\text { Glory }\end{array}$ & Disiiplin Kerja dan & Motiivasi Kerrja & Ter hadap & Kinerja Karyawan \\
\hline
\end{tabular}

\begin{tabular}{|l|}
\hline 1. Keteladanan \\
2. Balas jasa \\
3. Sikap adil \\
4. Sanksi hukum \\
5. Ketegasan \\
Hasibuan (2014:76) \\
\hline 1. Fisiologi \\
2. Rasa “aman \\
3. Sosiial \\
4. Har ga diiri \\
5. Aktualiisasi \\
Mangkunegara (2015: 110) \\
\hline
\end{tabular}

\section{Kiinerja Karyawan(Y)}

1. Jumlah Pekerjaan

2. Kualitas Pekerjaan

3. Ketepatan Waktu

4. Kehadiran

5. Kemampuan

Bangun (2012)

\section{Gambar 1 Kefrangka Berfikir}


Hipotesis Penelitian

lalah asumsi sementara yang berkenaan ringkasan perkara penelitian. Hipotesis ini bisa dilihat sebagai media yang berperan penting pada aktivitas industry atau perserikatan ini baik dalam mengoperasikan instrument kerja dan teori. Hakikatnya dengan adanya hipotesis bisa dikatakan bahwasannya suatu teori akan diterima dan teori lainnya tidak. Bersifat praduga sehingga sebelum membuat keputusan, hipotesis hendaknya dites terlebih dahulu kebenarannya menggunakan data pengamatan berdasarkan fakta yang dikumpulkan melalui proses penelitian ilmiah. Untuk bisa memperoleh tanggapan, respon, dan perolehan hasil yang belum tetap. Berpijak dari latar belakang fenomena tersebut, dibisakan dua dugaan sementara sebagai hasil riset ini. Lainnya yaitu untuk dijadikan pengarahan dalam keberlangsungan riset, sebagai pemandu, serta landasan untuk memaparkan ringkasan yang akan diwujudkan.

H1 : Dispilin berpengaruh positif dan signifikan terhadap kinerja

$\mathrm{H} 2$ : Motivasi berpengaruh positif dan signifikan terhadap kinerja

H3 : Disiplin dan Motivasi berpengaruh positif dan signifikan terhadap kinerja

\section{B. KAJIAN LITERATUR}

\section{Disiplin}

Dimaknai wujud Tindakan eksekutif menegakan ketertiban baku industry. Dimaknai juga pengembangan watak dan penanganan diri secara sukarela pada tata cara, prinsip, \& larangan baik tertulis maupun tidak. Jika semua dilema tidak dipedulikan maka dipastikan muncul penurunan benefit dan berefek buruk dalam kegiatan industry.

Terciptanya rasa kepekaan terhadap sesama pekerja adalah bagian manfaat berkembangnya kedisiplinan akan membentuk nilai tambah bagi industry. Hasil dan tujuan primer kedisiplinan yakni mengurangi dan membatasi perkara sebagai dampak ketidakdisiplinan. Tindakan pendisiplinan akan berpengaruh dan menaikkan moral, maslahat pekerja serta menjaga bakunya ketertiban industri. Apabila pekerja lebih menghormati kebiasaan yang ada maka kemungkinan bisa mengurangi sanksi kedisiplinan. Konteks ini dibutuhkan masing-masing pekerja demi menunjang dan memicu timbulnya kepribadian positif pegawai, senantiasa menunjukkan output kerja semaksimal mungkin.

\section{Motivasi}

Simpulannya ialah keyakinan priadi bahwa kadar upaya \& rampung nya daya yang dilakukan mampu menuntunnya ke peningkatan performa positif.

Selain itu, motivasi sanggup mengarahkan pribadi turut berbuatan yang berkaitan dalam energi pengharapan. Dengan label lain, semakin akbar upaya \& daya pribadi maka meningkat jua output kerjanya. seumpama diteliti lebih jauh, terdapat tiga dugaan variabel yaitu daya Tarik, interaksi prestasi kerja menggunakan imbalan, \& jua interaksi antara upaya menggunakan prestasi output kerja. Semua dugaan pada atas diyakini saling berhubungan.

\section{Hasil kerja}

Performa pekerja yang bagus akan mencerminkan hasil yang berpengaruh besar dalam perkembangan industry perusahaan. Sebaliknya hasil kerja yang buruk akan berdampak buruk pula pada pada industry. Hasil performa pekerja bisa dilihat dari aspek kualitas, kuantitas, waktu hasil kerja, serta teamwork agar bisa mencapai goal yang sudah dipaparkan oleh industry. Selain itu, hasil kerja pekerja bersifat individu maka dari itu setiap pekerja memiliki kemampuan yang berbeda dalam kaitan dengan tugasnya. Hasil kerja adalah aksi yang bermakna terdiri dari banyak elemen, unsur, bagian. 


\section{METODOLOGI PENELITIAN}

Wadah ulasan berada di Glory Store Tangerang Selatan di Kompleks Anggrek Loka Blok AD 21/22 BSD. Di ulasan ini memakai cara kuantitatif yang menguraikan gayutan sentral elastis independen atas elastis dependen. Penelaah mencoba menjelaskan tema yang akan diangkat.

Populasi di ulasan ini ialah tenaga Glory Store, yang semuanya 67 orang. Ulasan ini memakai asal data yaitu petunjuk esensialserta subordinat. ulasan ini memakai angket dengan skala likert yang dipakai 5 kelas melalui skala 5 :

$\begin{array}{ll}\text { Menentang } & \text { : Satu } \\ \text { Bertentangan } & \text { : Dua } \\ \text { Independen } & \text { : Tiga } \\ \text { Sependapat } & \text { : Empat } \\ \text { Sangat sependapat } & \text { : Lima }\end{array}$

Ulasan memakai uji keabsahan, uji reabilitas, uji pengujian normalitas, uji auto korelasi, uji heteroskedastisitas, uji koefisien degenerasi linier sederhana, uji penetapan, uji t, dan uji F. Populasi, Menurut Sugiyono (2012:80) "Populasi ialah area generalisasi yang terdiri dari objek/subjek yang punya kualitas dan karekteristik tertentu yang ditetapkan oleh pengulas untuk dipelajari dan terus diambil kesimpulannya." Populasi pada ulasan ini ialah Semua pekerja 67 orang.

Sampel, Berdasarkan Sugiyono (2012:81) "Sampel bisa diartikan sebagai suatu bagian yang ditarik dari popolasi teknik sampling yang digunakan pada ulasan adalah sampel jenuh. Sampel jenuh ialah bila semua populasi digunakan sebagai sampel (sugiono, 2012:68) jadi, sampel dalam ulasan ini 67 orang.

Sumber Data, terdiri dari:

\section{1) Data Primer}

lalah data yang didapat langsung lewat objek ulasan berupa dokumen-dokumen penting yang berpautan dengan urusan yang diulas.

\section{2) Data Sekunder}

Ialah data yang didapat dari usul-usul media dan elektronik. Dalam memenuhi ulasan untuk mendapat data, maka penulis akan memakai cara penulisan lewat :

a) Studi Kepustakaan Ulasan kepustakaan ini dijalankan dengan membaca literatur yang ada dan tulisan yang didapat di kuliah, baca buku-buku saran yang ada kaitannya dengan perkara yang akan dibahas.

b) Studi Lapangan

Pada ulasan lapangan ini penulis langsung mamapir ke industri yang jadi sasaran ulasan dan penimbunan data yang diperlukan dengan cara :

1) Observasi

Observasi yaitu awal semua ilmu pengetahuan, Nasution (1998) dalam Sugiyono (2017:226). Para ilmuwan hanya dapat kerja berdasarkan data, yaitu kisah asli tentang dunia nyata yang kedapatan lewat observasi.

2) Kuesioner Kuesioner ialah cara penimbunan data yang dilakukan pake cara ngasih seperangkat cetusan atau tebakan tertulis ke responden buat dijawabnya. 


\section{Kiat Analisis Data}

\section{Uji Validitas}

Validitas ialah derajat ketepatan antara data yang terjadi pada objek ulasan dengan daya yang nisa diaadukan oleh pengulas (Sugiyono 2017 :267).

2. Uji Reliabilitas

Diulasan ini buat uji reliabilitas memakai sistem internal consistency. Pernyatan Sugiyono (2014:168) "Peralatan yang terbukti bila dipakaikan berulangiulang buat ngukur objjek yang serupa, membuat kesamaan indikasi .

\section{Analisis Koefisien Kolerasi}

Kutipan Sugiono (2012:180), guna pertama dari analisis kolerasi ialah buat menetapkan seberapa erat hubungan antara variabel satu ke yang lainnya. analisis kolerasi di ulasan ini biar tahu semana besaar hubungan aspek $\mathrm{x}$ dan aspekj $\mathrm{y}$.

\section{Uji R egresi Linier Berrganda}

\section{HASIIL SERTA PEMMBAHASAN}

"Uji Valiiditas

Tabl 1 outt put pengujian Valiiditas Data

\begin{tabular}{|c|l|c|c|}
\hline No. & \multicolumn{1}{|c|}{ Pernyataan } & Kriteria & Kesimpulan \\
\hline 1 & Disiplin $\left(\mathrm{X}_{1}\right)$ & $\mathrm{r}_{\text {hitung }}>\mathrm{r}_{\text {tabel }}$ & Valid \\
\hline 2 & Motivasi kerja $\left(\mathrm{X}_{2}\right)$ & $\mathrm{r}_{\text {hitung }}>\mathrm{r}_{\text {tabel }}$ & Valid \\
\hline 3 & Kinerja $(\mathrm{Y})$ & $\mathrm{r}_{\text {hitung }}>\mathrm{r}_{\text {tabel }}$ & Valiid \\
\hline
\end{tabular}

Informasi ini menyatakan semua aspek memenuhi kriteria Kevalidan Hasil Uji Reabilitas

Tabl 2 outt put Reliiabilitas

\begin{tabular}{|c|l|c|c|c|}
\hline No. & \multicolumn{1}{|c|}{ Pernyataan } & $\begin{array}{c}\text { Chronbatch } \\
\text { Alpa }\end{array}$ & $\begin{array}{c}\text { Satandar } \\
\text { Chronbatch } \\
\text { Alpa }\end{array}$ & Kesimpulan \\
\hline 1 & Disiplin $\left(\mathrm{X}_{1}\right)^{\prime}$ & ${ }^{\prime}{ }^{\prime} .871$ & 0.60 & Reliabell \\
\hline 2 & Motiivasi kerja $\left(\mathrm{X}_{2}\right)^{\prime}$ & $0^{\prime} .822$ & 0.60 & Reliabell \\
\hline 3 & Kiinerja $(\mathrm{Y})^{\prime}$ & ${ }^{\prime} \mathrm{O}^{\prime} .874$ & 0.60 & Reliabe'l \\
\hline
\end{tabular}

Tabel 2 membuktikan bahwa semua variabel Reliable

Tabl 3 out putt pengujian normaliitas

\begin{tabular}{|c|c|c|}
\hline & & Resiidual \\
\hline N" & & 64 \\
\hline Norml Parameter a.b & Meean & .0000000 \\
\hline & S Deviati & 4.08386281 \\
\hline & Ab solute & .069 \\
\hline Mos t Ex treme & Po sitive & .050 \\
\hline & Nega tive & -.069 \\
\hline Tess Stactistic & & .069 \\
\hline ‘ & & '.200c’ \\
\hline
\end{tabular}




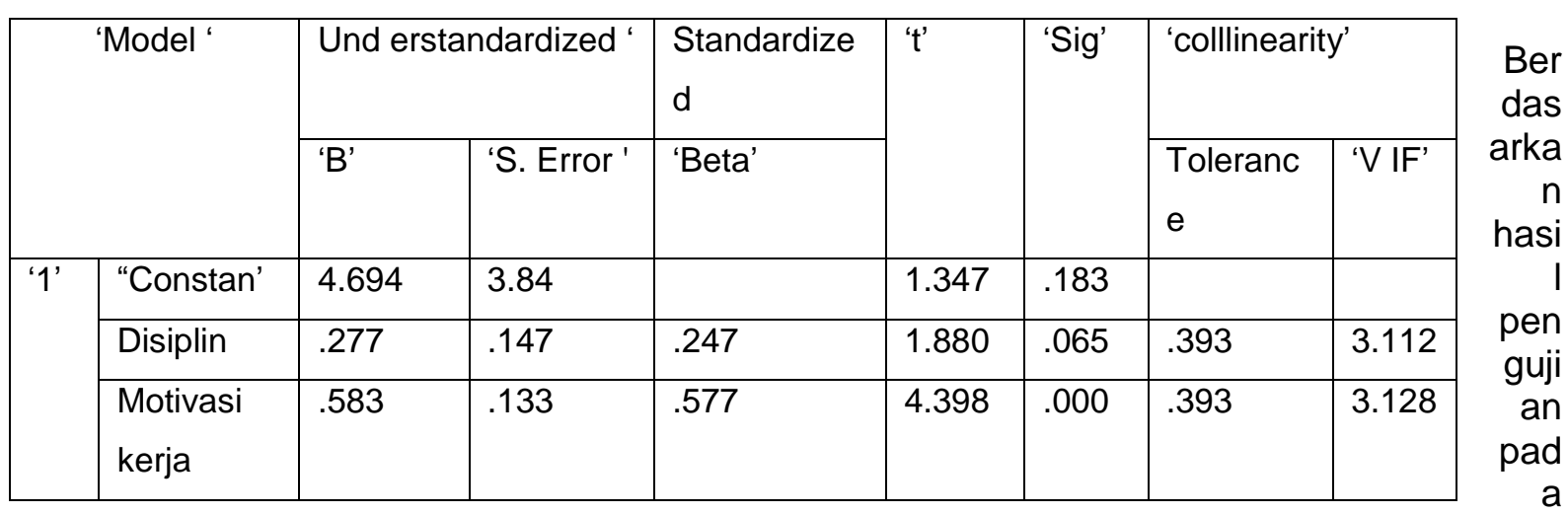

info diatas, ditemukan poin signifikan poin diatas lebih besar poin $\alpha=0,05(0,200>0,05)$. Oleh karena itu,maka perkiraan distribusi persamaan di uji ini normal.

Tabel 4 Hasil uji Multikolinieritas

Table 4 membuktikan poin 'V IF' $<10$ maka dalam uji ini tidak terjadi Multikolinieritas

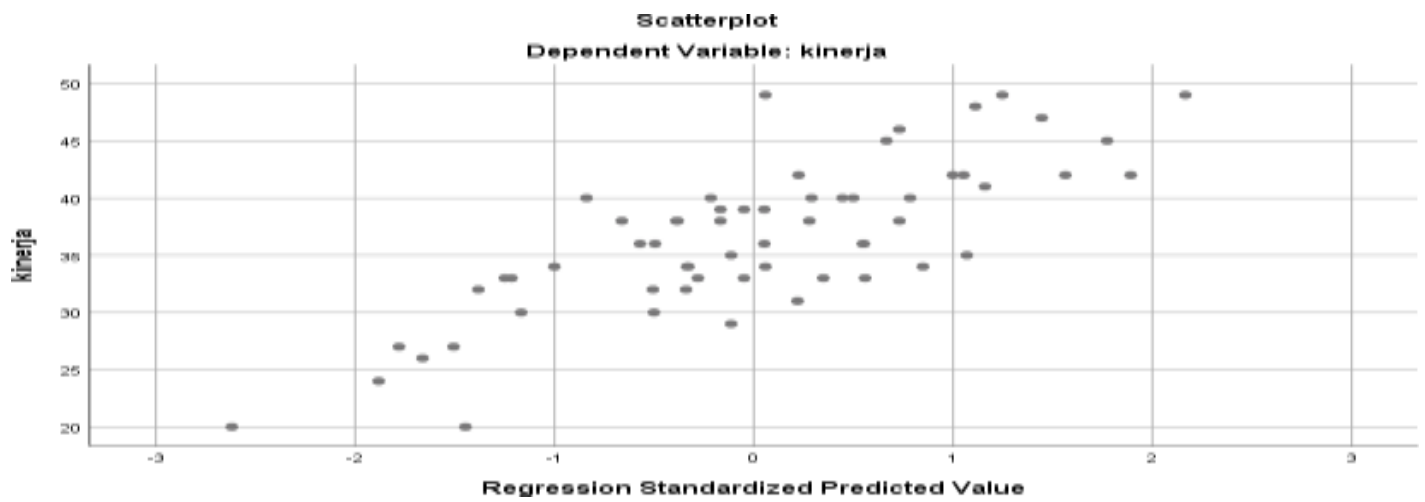

Gbr 2 Scatter plot Heteros kedastisiinitas

sketsa diatas menjelaskan bahwasanya tidak terjdi problem heteros kedastiisitas.

Tabel 5 Ha sil ujiRegresi LinierBerganda

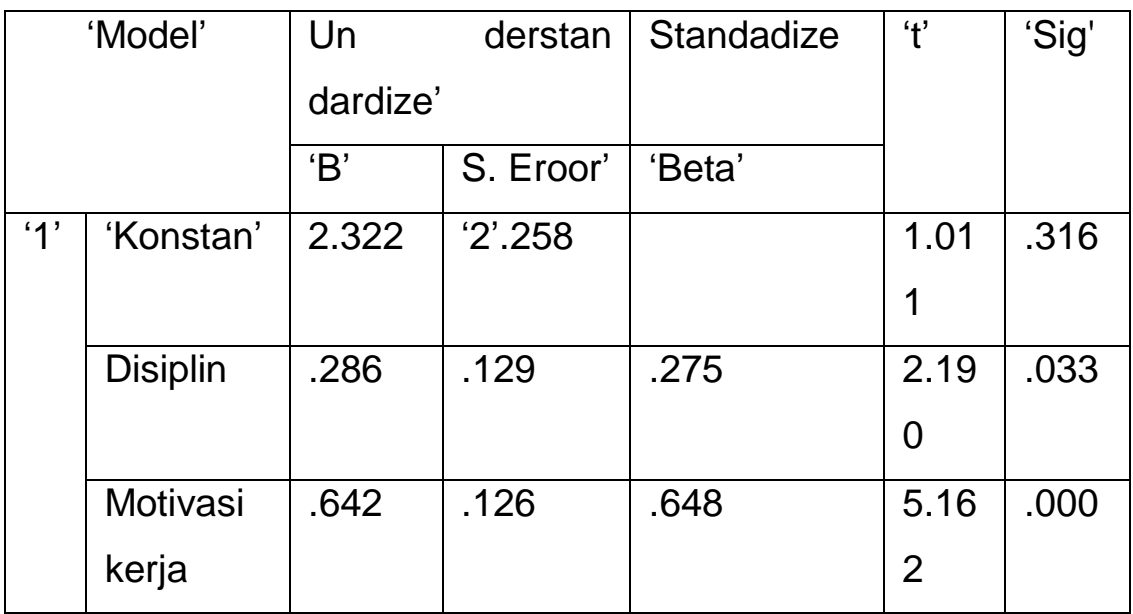


analisis degresi , ketetapannya sebagai berikut:

$$
Y=2,322+0,286 X 1+0,642 X 2
$$

Ketepan:

1) Niilai konstanta aspek displin 2,322 , motiivasi kerja karyawan hasilnya kosong atau tidak meningkat, 0,316 >0,05.

2) Poinregresi $0,286 \times 1$ esensinya saat disiplin memuncak 1 komponen, aspek motivasi kerja (X2) tak adaperubahan, asspek ambisi pekerja mengalami pemuncakan 0,286 .

3) Poinregresi $0,642 X 2$ esensinya diisaat motivasi kerja memuncak 1 komponen, sedangkan takada pergantian disiplin(X1) ,aspek ambisi pekerja menjalani pemuncakan 0,642 .

Tabel 6 Hasiil Koef isien Ko relasi (Simultan) aspek Di siplin(X1) \& Motivasi ke rja kepada performa pekerja'(Y)"

\begin{tabular}{|c|c|c|c|c|}
\hline & & 'DISI PLIN' & $\begin{array}{l}\text { 'MOTIVASI } \\
\text { KE RJA' }\end{array}$ & 'KI NERJA' \\
\hline \multirow[t]{3}{*}{$\begin{array}{l}\text { 'DISI PLIN } \\
\text { KERJA' }\end{array}$} & $\begin{array}{l}\text { "Pe arson } \\
\text { Co rrelation" }\end{array}$ & 1 & $.779^{* *}$ & $.698^{* *}$ \\
\hline & & & 0.000 & 0.000 \\
\hline & 'N' & 64 & 64 & 64 \\
\hline \multirow{3}{*}{$\begin{array}{l}\text { MOTIVA } \\
\text { SI } \\
\text { KERJA }\end{array}$} & $\begin{array}{l}\text { 'Pe arson } \\
\text { Co rrelation' }\end{array}$ & .779 & 1 & $.778^{*+2}$ \\
\hline & & 0 & & 0 \\
\hline & N" & 64 & 64 & 64 \\
\hline \multirow[t]{3}{*}{ KINERJA } & $\begin{array}{l}\text { Pe arson } \\
\text { Cor relation }\end{array}$ & $.698^{* *}$ & $.778^{* *}$ & 1 \\
\hline & & 0 & 0. & \\
\hline & "N & 64 & 64 & 64 \\
\hline
\end{tabular}

Tabel 6 menginformasikan bahwa hubungan aspek $X 1$ kepada $Y$ kuat dan $X 2$ kepada " $Y$ sangat kuat

Table 7 menjelaskan ada dominasi "signifikan antara Variabel /aspekX1 kepada "Y

Tabel 7 out put Uji " $t$ aspek Disiplin kepada performa pekerja “(Y)

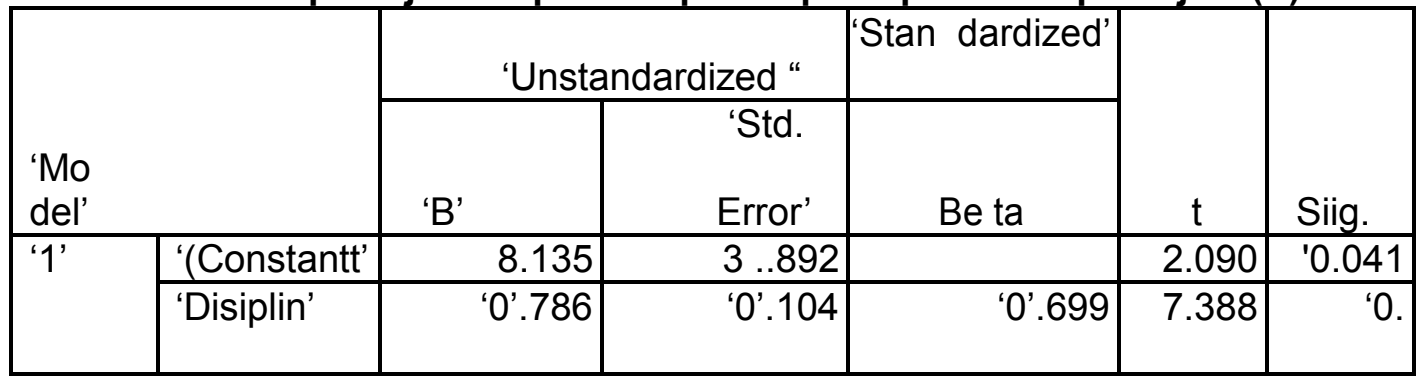




\begin{tabular}{|c|c|c|c|c|c|c|}
\hline \multirow{2}{*}{\multicolumn{2}{|c|}{ Mo del }} & \multicolumn{2}{|c|}{ Underst andardized } & \multirow{2}{*}{$\begin{array}{l}\text { Stan dardized } \\
\text { B eta }\end{array}$} & \multirow[t]{2}{*}{ T" } & \multirow[t]{2}{*}{ Sig" } \\
\hline & & $\mathrm{B}$ & St E rror & & & \\
\hline 1 & Kon stan & 7.498 & 3.215 & & 2.332 & 0.023 \\
\hline & $\begin{array}{l}\text { Motiivasi } \\
\text { kerrja }\end{array}$ & 0.779 & 0.082 & 0.770 & 9.161 & 0.000 \\
\hline
\end{tabular}

Tabel 9 out put Pengujian "F Siimultan

\begin{tabular}{|c|c|c|c|c|c|c|}
\hline \multicolumn{2}{|c|}{ ‘Model' } & \multirow{2}{*}{$\begin{array}{l}\text { 'Sum of } \\
\text { Squares' } \\
1572.940\end{array}$} & \multirow{2}{*}{\begin{tabular}{r|}
$d \mathrm{df} '$ \\
2 ' \\
\end{tabular}} & \multirow{2}{*}{$\begin{array}{l}\text { ‘Mean S } \\
\text { quare' } \\
786.468 \\
\end{array}$} & \multirow{2}{*}{$\begin{array}{l}\text { 'F' } \\
45.561\end{array}$} & \multirow{2}{*}{$\begin{array}{r}\text { 'Sig' } \\
.000^{\mathrm{b}}\end{array}$} \\
\hline ' 1 ' & 'Regression' & & & & & \\
\hline & Residual & 984.010 & 57 & 17.263 & & \\
\hline & Total & 2556.950 & 59 & & & \\
\hline
\end{tabular}

Table 9 menjelaskan bahwa adanya dominasi substansial bersamaan aspek " $\mathrm{X} 1$, $\mathrm{X} 2$ kepada $Y$

\section{E. KESIMPULAN}

Disiplin serta ambisi kerja bersama berimbas substansial kepada performa pekerja persamaandekadasi $Y=2,282+0,278 \times 1+0,639 \times 2$. Poin "determinasi sebanyak 61,5 persen maknanya variabel lepas dan aspek yang memiliki ikatan kuat, 38,5persen dipengaruhi hallainya. Didapat FHitung nya melebihi Ftabel (4 5,55 8 melebihi 3,1 60). Bermakna adanya dominasi yang substansial selaku "simultan dian tara disiplin serta ambisi kerja kepada performa pekerja glory store.

Indikator yang lemah lalah disiplin kerja poin yang didapat 3,64, agar menjadi lebih baik lagi Industry harus melangsungkan seleksi ketat serta pembagian tambahan extra bonus dan hadiiah.

\section{DAFTAR PUSTAKA}

Dessler. (2015). Manajemen Sumber Daya Manusia . Jakarta .

Ghozal, I. (2018). Aplikasi Analisis Multvariate dengan Program IBM SPSS . Semarang: UNDIP.

Hasibuan, M. S. (2016). Manajemen Sumber Daya MAnusia . jakarta: PT. Bumi Aksara.

Johanes, A. P. (2016). Pengaruh Motivasi dan Disiplin Kerja terhadap KInerja Pegawai pada Dinas Pertanian Kabupaten Supiori. Agri-Sosio Ekonomi.

Kadim, A., Sunardi, N., Lesmana, R., \& Sutarman, A. (2019). Revitalisasi Fungsi Masjid Sebagai Pusat Penguatan Manajemen Peternak Sapi Rakyat melalui Lembaga Pemberdayaan Masyarakat Terpadu (LEMPERMADU).(Studi Kasus di Masjid Ainul Yaqin Kel. Jontlak, Kec. Praya, Kab. Lombok Tengah, Provinsi Nusa Tenggara Barat). Jurnal Abdi Masyarakat Humanis, 1(1). 
Lesmana, R., Sunardi, N., \& Kartono. The Effect of Financing and Online Marketing on MSMEs Income Increasing at Intermoda Modern Market BSD City Tangerang Selatan. American Journal of Humanities and Social Sciences Research (AJHSSR), 5(7), 25-34

Lesmana, R., Sutarman, A., \& Sunardi, N. Building A Customer Loyalty Through Service Quality Mediated by Customer Satisfaction. American Journal of Humanities and Social Sciences Research (AJHSSR), 5(3), 38-45

Malayu, H. (2017). Manajemen Sumber Daya Manusia. Bandung: PT. Bumi Aksara.

Mangkunegara, A. (2015). Manajemen Sumber Daya Manusia Perusahaan . Bandung: Remaja Rosdakarya.

Mangukunegara, A. (2013). Manajemen Sumber Daya Manusia Perusahaan . Bandung: R emaja Rosdakarya.

Sinuliangga, N. (2016). Pengaruh Motivasi dan Kedisiplinan Kerja Terhadap Kinerja Pegawai Dipt. Bank Rakyat Indonesia (persero) Tbk. Cabang Medan Putri Hijau . Jurnal Penusa.

Sugiyono. (2016). Metode Penelitian Kuantitatif, Kualitatif dan R\&D. Bandung: PT. Alfabet.

Sugiyono. (2017). Metode Penelitian Kuantitatif, Kualitatif dan R\&D. Bandung: PT. Alfabet.

Sujarweni V, W. (2016). Kupas Tuntas Penelitian Akutansi dengan SPSS. Yogyakarya : Pustaka Baru.

Sunardi, N., \& Lesmana, R. (2020). Konsep Icepower (Wiramadu) sebagai Solusi Wirausaha menuju Desa Sejahtra Mandiri (DMS) pada Masa Pandemi Covid19. JIMF (Jurnal Ilmiah Manajemen Forkamma), 4(1).

Susanti, F. (2019). Budaya Organisasidan Disiplin Kerja Terhadap KInerja Karyawan Pada Klinik Tumbuh Kembang Yamet. JENIUS (Jurnal IImiah Manajemen Sumber Daya Manusia ).

Susanti, F. (2019). Pengaruh Pelatihan dan Komunikasi terhadap Kinerja Karyawan pada Klinik Tumbuh Kembang Yamet Pamulang. SEMARAK.

Sutrisno, E. (2014). Manajemen Sumber Daya Manusia . Jakarta: Pranada Media Grup.

Sutrisno, E. (211). Manajemen Sumber Daya Manusia . Jakarta : Kencana. 